\title{
Disfonia infantil: Análise dos distúrbios vocais em grupo de escolares
}

\author{
Children's dysphonia: Analysis of vocal disorders in a group of schoolchildren
}

\author{
Arachane Noronha $^{\natural}$, Thais Eloisa Toneli ${ }^{\natural}$, Daniela Ferro ${ }^{*}$, Patrícia Zart ${ }^{\natural}$, Luciana Grolli \\ Ardenghi ${ }^{6}$
}

Curso de Fonoaudiologia, Universidade de Passo Fundo, Passo Fundo, Rio Grande do Sul, Brasil. *Autor para

correspondência. E-mail: daniferro.fono@gmail.com

\begin{abstract}
Resumo: Introdução: A voz ocupa um papel muito importante na vida das pessoas desde a infância e somente com uma boa saúde vocal pode ser estabelecida uma comunicação eficaz. Objetivo: Analisar a qualidade vocal de crianças com idades entre 7 e 8 anos, identificando a prevalência de algum aspecto vocal e verificando a percepção dos pais em relação à voz de seu filho. Material e métodos: Estudo transversal, realizado com escolares e seus respectivos pais, onde os dados foram coletados por meio da gravação da voz e analisados através da Escala RASATI. A percepção dos pais com relação à voz de seu filho foi avaliada através de um questionário. Resultados e discussão: A soprosidade foi a qualidade vocal mais encontrada nas crianças $(76,47 \%)$, seguida de aspereza $(41,17 \%)$, rouquidão $(35,29 \%)$ e tensão $(17,64 \%)$. Referente ao questionário, $44 \%$ dos pais relataram alteração vocal quando seu filho fica nervoso, $52 \%$ quando grita muito e $56 \%$ quando volta da escola, festas ou jogos. Dos bons hábitos vocais, $92 \%$ referiram beber água, $88 \%$ dormir bem e $84 \%$ descansar. E dos hábitos vocais ruins, $76 \%$ dos pais consideraram falar muito em lugares barulhentos, $60 \%$ respirar pela boca, $52 \%$ tossir e $44 \%$ gritar. Conclusão: Os pais percebem as alterações vocais que os filhos apresentam e procuram alternativas de melhora, porém não sabem identificar hábitos saudáveis ou prejudiciais à voz. Assim, nota-se a importância das orientações aos pais sobre os cuidados vocais das crianças.
\end{abstract}

Palavras-chave: voz, qualidade da voz, distúrbios da voz, criança, comportamento infantil.

\begin{abstract}
Introduction: The voice has played a very important role in people's lives since childhood and only with good vocal health can effective communication be established. Objective: Cross-sectional study, carried out with schoolchildren and their respective parents, where data were collected through voice recording and analyzed using the RASATI Scale. Parents' perception of their child's voice was assessed using a questionnaire. Material and methods: A cross-sectional study was carried out with group of schoolchildren and their respective parents, where data were collected through voice recording and analyzed using the RASATI Scale. Parents' perception of their child's voice was assessed through a questionnaire. Results and discussion: The most common vocal quality was soprosity found in children (76.47\%), followed by roughness (41.17\%), hoarseness (35.29\%) and tension (17.64\%). Regarding the questionnaire, $44 \%$ of parents reported vocal alteration when their child became nervous, $52 \%$ when they cried a lot and $56 \%$ when they returned from school, parties or games. Of the good vocal habits, $92 \%$ reported drinking water, $88 \%$ sleeping well and $84 \%$ resting. And of bad vocal habits, $76 \%$ of parents considered talking loudly in noisy places, $60 \%$ breathing through the mouth, $52 \%$ coughing and $44 \%$ screaming. Conclusion: Parents perceive the vocal changes that their children present and seek alternatives for improvement, but they do not know how to identify healthy or harmful habits. Thus, we note the importance of parents' guidance on the vocal care of children.
\end{abstract}

Keywords: voice, voice quality, voice disorders, child, child behavior.

\section{Introdução}

A voz ocupa um papel muito importante na vida das pessoas, pois é o meio mais utilizado para a comunicação e relacionamento interpessoal (Pascotini, Vanessa, Leris, \& Carla, 2015). Qualquer dificuldade na emissão vocal, que impeça a produção da voz de forma natural, pode trazer prejuízos à comunicação e o desenvolvimento vocal sofre as influências do meio e cultura em que estão inseridas (Guerra, Araújo, Lira, Lucena, \& Gomes., 2014). Quando a produção vocal é realizada com esforço, sem harmonia, limitando o 
indivíduo na transmissão de sua fala verbal e emocional, pode-se dizer que há um transtorno vocal denominado disfonia (Paixão, Silvério, Berberian, Mourão, \& Marques., 2012).

Na infância, as alterações de voz podem afetar os desempenhos escolares, sociais e emocionais, podendo também refletir problemas no desenvolvimento da capacidade de comunicação na vida adulta (Tavares, Labio, \& Martins, 2010).

Estudos demonstraram que a prevalência de alterações vocais na infância é de $6 \%$ a 38\%, sendo que destas, $92 \%$ podem ter sido originadas do comportamento vocal inadequado, onde $53 \%$ apresentaram nódulo e $21 \%$ cisto (Ramos, Souza, \& Gama, 2017). As alterações vocais encontradas frequentemente são a rouquidão e a soprosidade (Oliveira, Teixeira, Gama, \& Medeiros, 2011), alteração de ressonância com predomínio de foco ressonantal, voz muito fraca ou muito forte em intensidade, velocidade acelerada ou excessivamente reduzida, frequência muito alta ou muito baixa para a idade (Behlau \& Gonçalves, 1988), sendo a maior ocorrência em crianças entre cinco e dez anos de idade (Pascotini et al., 2015). Apresentam, também, uma redução dos tempos máximos fonatórios, incoordenação pneumofonoarticulatória, pitch e loudness inadequados (Ribeiro, Leite, Alencar, Bail, \& Bagarollo, 2013).

A formação do padrão vocal infantil está intimamente ligada a modelos vocais presentes no ambiente em que as crianças vivem. Portanto, pais e demais membros da família têm papel fundamental nas condições vocais das crianças, podendo influenciar os quadros de disfonia infantil. Apesar de tal influência, pais e educadores na maioria das vezes dão pouca importância a estas alterações, dificultando a identificação e reconhecimento da disfonia e os fatores de risco que podem acarretar tal quadro, bem como suas implicações para a criança (Paixão et al., 2012).

A competição sonora e o estresse que as crianças vêm sofrendo no seu dia a dia são causas importantes quanto ao grande número de incidências de distúrbios vocais na infância. A esses fatores acrescenta-se o mau uso ou abuso da voz, os quais podem danificar os delicados tecidos da laringe e produzir distúrbios vocais sérios. Estudos apontam que as formas de abusos vocais mais comuns realizados pelas crianças são falta de hidratação no organismo, gritar ou falar com esforço, utilizar golpe de glote, falar forte ou com voz soprada, falar em ambientes secos e empoeirados ou de fumantes, praticar atividade físicas falando, rir alto ou chorar em excesso, discutir com frequência, praticar corais ou teatros infantis sem orientação vocal especializada e descuidar da alimentação saudável (Pinho, Jarrus, \& Tsuji, 2004).

A maioria dos pais que convivem com crianças que apresentam comportamento vocal inadequado dificilmente procuram um fonoaudiólogo, pediatra ou um professor, com queixa que seu filho é rouco (Von Fritsch, Oliveira, \& Behlau, 2011). Normalmente, os pais descrevem essas crianças com as seguintes características: não param, gritam muito, são difíceis de lidar, falam o tempo todo e alto (Wilson, 1993). Acredita-se que a falta de intervenção aconteça pela insuficiência de orientação aos pais em relação à identificação dos sinais de riscos vocais em seus filhos (Von Fritsch et al., 2011).

As alterações de voz na infância interferem de modo negativo no desempenho social ou mesmo no desenvolvimento afetivo-emocional de qualquer criança (Ribeiro et al., 2013). Por ocorrerem em uma fase de formação de caráter e personalidade, os problemas de voz na infância requerem sempre uma investigação precisa (Takeshita, Aguiar-Ricz, Isaac, Ricz, \& Anselmo-Lima, 2009).

Portanto, o diagnóstico e o tratamento precoce das disfonias infantis são de extrema importância para que estas não interfiram na capacidade comunicativa na fase adulta (Souza, Nunes, Lima Friche, \& Gama, 2017).

Deste modo o presente estudo teve como objetivo analisar através da Escala RASATI a qualidade vocal de crianças com idades entre 7 e 8 anos, identificando as alterações vocais mais comuns e comparando com a percepção dos pais quanto ao comportamento e características vocais de seus filhos.

\section{Material e métodos}

O presente estudo recebeu a aprovação do Comitê de Ética e Pesquisa (CEP), sob o número de registro, $108572 / 2016$.

Realizou-se esta pesquisa junto a duas escolas, uma estadual e uma municipal, no município de Arvorezinha- RS, com as turmas do segundo ano escolar, totalizando quatro turmas.

O período de coleta de dados ocorreu entre dezembro de 2016 e abril de 2017. Os critérios de inclusão foram crianças do segundo ano escolar, com idade entre 7 e 8 anos, ambos os gêneros, onde os pais ou responsáveis tivessem assinado o Termo de Consentimento Livre e Esclarecido (TCLE) e respondido o questionário (Tabela 1). Sendo excluídas da pesquisa as crianças que não estavam autorizadas a participar, aquelas em que os pais não responderam o questionário e as que apresentavam quadro gripal no momento da coleta. 
Os dados foram coletados através da aplicação da Escala RASATI (Pinho \& Pontes, 2002) e de um questionário não padronizado, elaborado e reorganizado conforme as necessidades e objetivos do presente estudo. O mesmo foi elaborado baseando-se no questionário, da dissertação de mestrado, realizado por Teixeira (2002), sendo esse, organizado através das informações do manual Higiene Vocal Infantil: Informações Básicas de Behlau e Gonçalves (1997).

Inicialmente enviou-se às escolas o Termo Institucional, solicitando a autorização da direção escolar para a realização da pesquisa, e aos pais dos alunos o Termo de Consentimento Livre e Esclarecido (TCLE). Após o retorno destes termos devidamente assinados pelos pais, iniciou-se a coleta dos dados. Foram enviados 70 TCLE, retornando 40 termos assinados. Após, foi encaminhado para os 40 pais, um questionário contendo 12 questões de múltipla escolha relacionadas à voz de seus filhos, alterações, hábitos e comportamentos vocais, onde os mesmos deveriam responder e encaminhar de volta para a escola, conforme a data estipulada pelas pesquisadoras.

Dos 40 questionários enviados, 26 retornaram respondidos. A partir deste momento iniciou-se a coleta das vozes das crianças, sendo que um sujeito foi excluído da pesquisa por apresentar quadro gripal. Portanto a amostra ficou composta por 25 participante, 15 (60\%) do sexo feminino e 10 (40\%) do sexo masculino.

As vozes das crianças foram gravadas na própria escola, em uma sala sem isolamento acústico, porém sem interferência de ruídos. A gravação foi realizada através do gravador de voz de um celular da marca Samsung Galaxy, modelo SM-G531H/DL, à distância de um palmo entre o aparelho e a boca da criança. Para a avaliação das vozes foi solicitado a fala dos números de 1 a 10, os dias da semana, meses do ano e cantar "Parabéns pra você".

Posteriormente, as vozes foram analisadas, por dois fonoaudiólogos qualificados na área de voz, e classificadas de acordo com a escala RASATI (Rouquidão, Aspereza, Soprosidade, Astenia, Tensão e Instabilidade).

Os resultados foram selecionados e agrupados em tabelas, realizando-se a análise percentual de respostas dos questionários e a classificação das vozes das crianças.

\section{Resultados}

Foram analisados os dados de 25 participantes, sendo 15 (60\%) do sexo feminino e 10 (40\%) do sexo masculino, onde 17 (68\%) apresentaram importantes alterações vocais. De acordo com a pesquisa realizada, obteve-se os resultados dos questionários preenchidos pelos pais, representados na Tabela 2 , e a classificação individual das alterações vocais através da aplicação da Escala RASATI, representada na Tabela 3.

A maior parte dos pais consideraram a voz do filho como normal, porém relataram perceber algum tipo de alteração vocal em seu filho em determinadas situações, principalmente, quando o filho está nervoso, grita muito, volta da escola, festas ou jogos.

Em relação à preocupação dos pais com as alterações vocais do filho, percebe-se que um pequeno número de pais realmente se preocupa com a voz de seu filho. Ainda, pode-se observar que os pais buscam meios de tratamento perante alterações vocais do filho, no entanto, não buscam um profissional da área da saúde. Além disso, nota-se um maior número de crianças que não percebem as próprias alterações vocais, e aquelas que percebem, sentem-se incomodadas e diminuem o uso da voz.

Os pais acreditam que a voz é muito importante para a vida pessoal e para o futuro de seu filho. Ainda, em relação aos hábitos vocais, percebe-se que existe falta de orientação neste aspecto, pois hábitos extremamente prejudiciais à voz foram assinalados como hábitos bons.

A tabela 3 mostra a análise vocal individual, através da Escala RASATI, das alterações vocais presentes nas crianças. Na análise dos resultados, observou-se que a soprosidade foi a qualidade vocal mais encontrada nas crianças, seguida de aspereza, rouquidão e tensão. Também, verificou-se um maior número de crianças que apresentaram duas alterações vocais.

\section{Discussão}

As alterações vocais na infância podem ser pouco percebidas e muitos pais tendem a considerar uma voz alterada como normal. Além disso, os pais geralmente confundem as alterações vocais com as infecções de via aérea superior. $O$ presente estudo propôs analisar o conhecimento dos pais em relação aos comportamentos, alterações e hábitos vocais de seus filhos através de um questionário e também avaliar a qualidade vocal das respectivas crianças através da Escala RASATI (Pinho \& Pontes, 2002).

Para que se tenha um funcionamento harmônico das estruturas que compõe o aparelho fonador é preciso uma produção vocal adequada, que resultará em uma voz equilibrada. Contudo, quando não há uma harmonia na produção da voz, podemos estar diante de uma disfonia. Crianças em idade escolar, podem apresentar problemas na voz decorrentes do mau uso ou abuso vocal (Oliveira et al., 2011). 
Tabela 1. Questionário da percepção dos pais sobre os aspectos vocais presentes em seu filho.
1) O seu filho é alérgico?
( ) $\operatorname{sim}($ ) não ( ) não sei

2) Você acha que a voz do seu filho é:

( ) normal ( ) rouca ( ) alterada ( ) nasal ( ) bonita ( ) muito alta ( ) feia ( ) muito baixa ( ) estridente ( ) irritante

3) Você percebe alterações na voz de seu filho quando:

( ) está nervoso ( ) nunca ( ) às vezes ( ) muitas vezes ( ) sempre

() grita muito ( ) nunca ( ) às vezes ( ) muitas vezes ( ) sempre

() canta ( ) nunca ( ) às vezes ( ) muitas vezes () sempre

( ) volta da escola () nunca ( ) às vezes ( ) muitas vezes ( ) sempre

( ) volta de festas ( ) nunca ( ) às vezes ( ) muitas vezes ( ) sempre

() volta de jogos ( ) nunca () às vezes ( ) muitas vezes () sempre

( ) volta de atividades ao ar livre ( ) nunca ( ) às vezes ( ) muitas vezes ( ) sempre

4) Você se preocupa com isso? ( ) $\operatorname{sim}()$ não ( ) às vezes

() pede para a criança parar de falar

() dá remédios caseiros para a criança

( ) procura o médico

5) $O$ que você faz quando isso acontece?

() procura o fonoaudiólogo

() outros
6) A criança percebe quando tem

algum problema na voz?

7)Seu filho se queixa de:
( ) $\operatorname{sim}$ ( ) não ( ) não tem problema na voz

( ) cansaço ou esforço ao falar ( ) às vezes ( ) muitas vezes ( ) sempre ( ) nunca

() dor ou ardor na garganta () às vezes ( ) muitas vezes ( ) sempre () nunca

( ) coceira na garganta ( ) às vezes ( ) muitas vezes ( ) sempre ( ) nunca

( ) secura na garganta () às vezes ( ) muitas vezes () sempre () nunca

() falta de ar quando fala muito ( ) às vezes ( ) muitas vezes ( ) sempre ( ) nunca

( ) dor no pescoço ou nuca ( ) às vezes ( ) muitas vezes ( ) sempre ( ) nunca

() rouquidão ( ) às vezes ( ) muitas vezes ( ) sempre () nunca ( ) outras queixas vocais. Quais?

( ) mudança na voz no decorrer do dia ( ) nunca ( )às vezes ( ) muitas vezes ( ) sempre

8) 0 seu filho apresenta:

9) 0 que a criança faz quando tem algum problema na voz?

10) Você acha que a voz de seu filho é importante para a vida:
( ) pessoal ( ) pouca importância ( ) importância média ( ) muita importância ( ) familiar ( ) pouca importância ( ) importância média ( ) muita importância () escolar ( ) pouca importância ( ) importância média ( ) muita importância ( ) para seu futuro ( ) pouca importância ( ) importância média ( ) muita importância

perda total da voz ( ) nunca () às vezes ( ) muitas vezes ( ) sempre

() rouquidão () nunca ()às vezes () muitas vezes () sempre

( ) sente-se incomodado

( ) diminui o uso da voz

() deixa de gritar

() faz gargarejos

() outros
11) Assinale com um (x) se os hábitos abaixo são bons ou ruins para a voz:

$\begin{array}{lc}\text { Gritar } & \text { ( )BOM ( )RUIM ( ) NÃO SEI } \\ \text { Cantar } & \text { ( )BOM ( )RUIM ( ) NÃO SEI } \\ \text { Falar muito } & \text { ()BOM ( )RUIM ( ) NÃO SEI } \\ \text { Tomar bebidas geladas } & \text { ( )BOM ( )RUIM ( ) NÃO SEI } \\ \text { Tossir } & \text { ()BOM ( )RUIM ( ) NÃO SEI }\end{array}$

Falar muito em lugares barulhentos ( )BOM ( )RUIM ( ) NÃO SEI

Usar spray ou pastilhas para garganta ()BOM ( )RUIM ( ) NÃO SEI

Gargalhar

( )BOM ( )RUIM ( ) NÃO SEI

Imitar outras vozes, animais ou ruídos ( )BOM ( )RUIM ( ) NÃO SEI

Sussurrar ( )BOM ( )RUIM ( ) NÃO SEI

Usar roupas apertadas ( )BOM ( )RUIM ( ) NÃO SEI

Beber bastante água ( )BOM ( )RUIM ( ) NÃO SEI

Respirar pela boca ()BOM ( )RUIM ( ) NÃO SEI

Dormir bem ( )BOM ( )RUIM ( ) NÃO SEI

Descansar ()BOM ()RUIM ( ) NÃO SEI

Tomar friagem
( )BOM ( )RUIM ( ) NÃO SEI

Cantar com frequência (

Imitar vozes de personagens ( )

Falar muito ()

Gritar com frequência () 
Disfonia Infantil: Análise dos distúrbios vocais em grupo de escolares

Tabela 2. Aspectos vocais presentes nas crianças de acordo com a percepção dos pais.

\begin{tabular}{|c|c|c|}
\hline Aspectos vocais presentes nas crianças & $\mathrm{N}$ & $\%$ \\
\hline \multicolumn{3}{|l|}{ Alergia } \\
\hline Sim & 10 & 40 \\
\hline Não & 15 & 60 \\
\hline \multicolumn{3}{|l|}{ Padrão Vocal } \\
\hline Normal & 10 & 40 \\
\hline Nasal & 1 & 4 \\
\hline Bonita & 5 & 20 \\
\hline Alterada & 2 & 8 \\
\hline 2 ou mais & 7 & 28 \\
\hline \multicolumn{3}{|l|}{ Alteração vocal } \\
\hline Às vezes quando está nervoso & 11 & 44 \\
\hline Às vezes quando grita muito & 13 & 52 \\
\hline Às vezes quando canta & 4 & 16 \\
\hline Às vezes quando volta da escola/festas/jogos & 14 & 56 \\
\hline Às vezes quando volta de atividades ao ar livre & 3 & 12 \\
\hline Muitas vezes quando está nervoso & 2 & 8 \\
\hline Muitas vezes quando grita muito & 1 & 4 \\
\hline Muitas vezes quando volta de atividades ao ar livre & 2 & 8 \\
\hline \multicolumn{3}{|l|}{ Preocupação perante as alterações } \\
\hline Sim & 6 & 24 \\
\hline Não & 9 & 36 \\
\hline Às vezes & 10 & 40 \\
\hline \multicolumn{3}{|l|}{ Atitude dos pais ao perceberem as alterações } \\
\hline Remédios caseiros & 3 & 12 \\
\hline Parar de falar & 4 & 16 \\
\hline Procura um médico & 1 & 4 \\
\hline Procura um fonoaudiólogo & 1 & 4 \\
\hline Duas ou mais & 1 & 4 \\
\hline Outros & 7 & 28 \\
\hline \multicolumn{3}{|l|}{ Percepção da criança nas alterações da sua própria voz } \\
\hline Percebe & 8 & 32 \\
\hline Não percebe & 11 & 44 \\
\hline Não tem problema & 6 & 24 \\
\hline \multicolumn{3}{|l|}{ Queixas vocais } \\
\hline Dor ou ardor na garganta às vezes & 4 & 16 \\
\hline Coceira na garganta às vezes & 1 & 4 \\
\hline Secura na garganta às vezes & 1 & 4 \\
\hline Duas ou mais às vezes & 9 & 36 \\
\hline \multicolumn{3}{|l|}{ Alterações na voz referida pelos pais } \\
\hline Mudança na voz no decorrer do dia às vezes & 3 & 12 \\
\hline Perda total da voz às vezes & 1 & 4 \\
\hline Rouquidão às vezes & 3 & 12 \\
\hline Duas ou mais às vezes & 4 & 16 \\
\hline \multicolumn{3}{|l|}{ Atitude da criança quando percebe alteração vocal } \\
\hline Diminui o uso da voz & 4 & 16 \\
\hline Sente-se incomodada & 4 & 16 \\
\hline Deixa de gritar & 2 & 8 \\
\hline Gargarejo & 2 & 8 \\
\hline Outros & 3 & 12 \\
\hline Duas ou mais & 3 & 12 \\
\hline \multicolumn{3}{|l|}{ Importância da voz para a vida da criança segundo os pais. } \\
\hline Pessoal & 3 & 12 \\
\hline Para seu futuro & 3 & 12 \\
\hline Duas ou mais & 19 & 76 \\
\hline \multicolumn{3}{|l|}{ Hábitos vocais bons relatados pelos pais } \\
\hline Cantar & 19 & 76 \\
\hline Falar muito & 13 & 52 \\
\hline Gargalhar & 14 & 56 \\
\hline Imitar & 12 & 48 \\
\hline Sussurrar & 15 & 60 \\
\hline Beber água & 23 & 92 \\
\hline Dormir bem & 22 & 88 \\
\hline Descansar & 21 & 84 \\
\hline
\end{tabular}




\begin{tabular}{ccc}
\hline Hábitos vocais ruins relatados pelos pais & & \\
Gritar & 11 & 44 \\
Bebidas geladas & 11 & 44 \\
Tossir & 13 & 52 \\
Falar muito (barulho) & 19 & 76 \\
Roupas apertadas & 14 & 56 \\
Respirar pela boca & 15 & 60 \\
Tomar friagem & 19 & 76 \\
\hline Atitudes que prejudicam a voz & & \\
Cantar & 1 & 4 \\
Falar muito & 7 & 28 \\
Imitar vozes & 2 & 8 \\
Duas ou mais & 13 & 52 \\
\hline
\end{tabular}

Tabela 3. Análise individual das alterações vocais presentes nas crianças através da Escala RASATI.

\begin{tabular}{|c|c|c|c|c|c|c|}
\hline Número de alterações & n (\%) & & Rouquidão & Aspereza & Soprosidade & Tensão \\
\hline \multirow[t]{7}{*}{ Uma } & $7(41 \%)$ & 1 & $1-2$ & - & - & - \\
\hline & & 2 & - & - & 1 & - \\
\hline & & 3 & - & - & 1 & - \\
\hline & & 4 & - & - & 1 & - \\
\hline & & 5 & - & - & - & 1 \\
\hline & & 6 & - & - & - & $1-2$ \\
\hline & & 7 & - & - & - & $1-2$ \\
\hline \multirow[t]{8}{*}{ Duas } & $8(47 \%)$ & 1 & 1 & - & 1 & - \\
\hline & & 2 & $1-2$ & - & 1 & - \\
\hline & & 3 & 2 & - & $1-2$ & - \\
\hline & & 4 & - & 1 & 1 & - \\
\hline & & 5 & - & 1 & 1 & - \\
\hline & & 6 & - & 1 & $1-2$ & - \\
\hline & & 7 & - & $1-2$ & 1 & - \\
\hline & & 8 & - & $1-2$ & $1-2$ & - \\
\hline \multirow[t]{2}{*}{ Três } & $2(12 \%)$ & 1 & 2 & $1-2$ & $1-2$ & - \\
\hline & & 2 & 2 & $1-2$ & 1 & - \\
\hline Total & 17 (100\%) & & $35,29 \%$ & $41,17 \%$ & $76,47 \%$ & $17,64 \%$ \\
\hline
\end{tabular}

Quando questionados sobre como consideram a voz de seu filho, $40 \%$ dos pais apontaram como normal e 2\% consideraram alterada, concordando com os estudos de Pascotini (2015) e Takeshita et al. (2009), onde mais de $60 \%$ dos pais classificaram a voz de seu filho como normal e mais de 30\% classificaram como alterada. Também foram anotadas as características vocais muito alta e irritante.

Em relação ao momento que os pais percebem alterações vocais em seu filho, destacou-se $56 \%$ de respostas quando estes voltam da escola, festas ou jogos. As situações de estar nervoso, cantar, gritar muito e voltar de atividades ao ar livre variaram de $52 \%$ a $4 \%$. No estudo de Pascotini et al. (2015), 65\% dos pais relataram que percebem alterações na voz de seus filhos quando estes estão nervosos.

Atualmente, as crianças estão expostas a muitos estímulos, atividades intensas, competições sonoras e influências ambientais, situações estas que favorecem o estresse e o abuso vocal, principalmente no ambiente escolar (Gomes, Lima, Silva, \& Lucena, 2016). Todos estes estímulos podem gerar estresse nas crianças, deixando-as nervosas, concordando assim, com os achados neste estudo.

Os pais quando questionados sobre quais alterações seu filho apresenta, $12 \%$ relataram mudança na voz no decorrer do dia, $4 \%$ perda total da voz, $12 \%$ relatam rouquidão, concordando com os estudos de Guerra et al. (2014) e Gomes et al. (2016) que apontam estas alterações sendo percebidas pelos pais. Já no estudo de Teixeira (2002) é relatado que $80 \%$ a 95\% dos pais responderam que não reconhecem estas alterações vocais em seus filhos.

Quanto à preocupação dos pais frente a essas alterações, a maioria deles, $40 \%$ relatam que se preocupa às vezes, $36 \%$ não se preocupam, sendo que apenas $24 \%$ se preocupam de fato com estas alterações. Pais e demais membros da família influenciam muito quanto ao modelo e condições gerais da voz, e apesar de tal influência, a maioria deles não dão a devida importância às alterações vocais da criança (Guerra et al., 2014). 
Possivelmente, os pais não se preocupam com determinadas alterações, pois pensam que a situação é normal, porém, a falta de atenção pode agravar a saúde vocal da criança.

Com relação às atitudes que os pais têm quando o seu filho apresenta algum tipo de alteração vocal, $16 \%$ responderam que pedem para a criança parar de falar, $12 \%$ oferecem remédios caseiros, e em outras situações procuram um médico $4 \%$ ou um fonoaudiólogo $4 \%$. Estes resultados concordam com a literatura consultada, onde $31 \%$ dos pais responderam que pedem para o filho parar de falar. Para a autora, este resultado mostra que os pais reconhecem que falar na presença de uma alteração na voz, prejudicará ainda mais a condição vocal (Teixeira, 2002).

Os pais foram questionados também sobre se o filho percebia quando tinha algum tipo de alteração na voz. Nossos estudos mostraram que $44 \%$ não percebem, $32 \%$ disseram que o filho percebe e $24 \%$ relatam que o filho não tem alteração vocal, o que corrobora com o estudo de Teixeira (2002) onde $36 \%$ dos pais responderam que acreditam que a criança não percebe e $27 \%$ que ela percebe. A partir disso, observa-se que uma alteração vocal não modifica a qualidade de vida para a criança, não afetando as atividades sociais, físicas ou de aspectos emocionais, por isso a maioria das crianças não percebem se a voz está normal ou alterada.

Muitas vezes, a alteração vocal é funcional e não gera desconforto ou dor. Este aspecto pode ser apontado quando se observam os resultados da questão sobre queixas vocais. Nesta questão, observa-se que as crianças pouco reclamam de alguma alteração vocal, pois $16 \%$ se queixam de dor ou ardor na garganta, $4 \%$ coceira na garganta, $4 \%$ secura na garganta, coincidindo com a literatura que aponta que poucas vezes as crianças apresentam queixas vocais (Teixeira, 2002).

Em relação às atitudes da criança na presença de alguma alteração vocal, 16\% diminui o uso da voz, 16\% sente-se incomodada, $8 \%$ deixa de gritar, $8 \%$ faz gargarejo, $12 \%$ realiza outros métodos, $12 \%$ responderam duas ou mais alternativas e 7\% não responderam à questão. Apesar da maioria dos pais relatarem que o seu filho não tem queixas vocais, as atitudes relatadas acima nos mostram que as crianças mudam seu comportamento vocal quando percebem que há algum problema.

Os pais foram questionados sobre a importância da voz para a vida familiar, escolar, pessoal e futuro de seu filho. Logo, $12 \%$ dos pais responderam ter muita importância na vida pessoal, $12 \%$ muita importância para o futuro e $76 \%$ assinalaram duas ou mais alternativas. A voz tem importante papel na vida das pessoas, ela é uma identidade e o recurso mais utilizado na comunicação e no relacionamento interpessoal (Pascotini et al., 2015).

Na questão em que os pais foram solicitados a relatar os bons e maus hábitos vocais de seu filho, $76 \%$ relataram que cantar é um bom hábito, 52\% falar muito, 56\% gargalhar, $48 \%$ imitar vozes, $60 \%$ sussurrar, $92 \%$ beber água, $88 \%$ dormir bem e $84 \%$ descansar. A literatura aponta que dormir bem e descansar são aspectos considerados bons para a voz, já que são importantes para a saúde em geral. Além disso, o hábito de beber água é essencial para uma boa voz, pois proporciona hidratação das pregas vocais melhorando sua função. Os pais citaram cantar e gargalhar para hábitos bons, o que não está errado, porém praticar o canto sem uma devida instrução poderá causar alterações vocais, e gargalhar dependendo de como é realizada pode ou não ser abusiva (Teixeira, 2002).

Alguns pais consideraram que imitar vozes, sussurrar e falar muito são hábitos bons para a voz. Pode-se perceber que os pais não reconhecem esses fatores como abusivos e prejudiciais à voz da criança, sugerindo uma falta de informação e orientação correta sobre hábitos vocais saudáveis.

Como hábitos ruins, $44 \%$ das respostas apontam para gritar, $44 \%$ ingerir bebidas geladas, $52 \%$ tossir, $76 \%$ falar muito em lugares barulhentos, $56 \%$ usar roupas apertadas, $60 \%$ respirar pela boca e $76 \%$ tomar friagem. Diferentes estudos relatam esses hábitos como sendo ruins para a voz (Pascotini et al., 2015; Paixão et al., 2012; Takeshita et al., 2009; Paixão et al., 2015). Quanto ao hábito de respirar com a boca aberta, estudos mostram que em respiradores orais, as funções estomatognáticas juntamente com a voz poderão estar alteradas. Nesses indivíduos a voz pode apresentar alteração no traço de sonoridade, ser rouca, hiper ou hiponasal (Tavares \& Silva, 2008). As opções usar roupas apertadas e tomar friagem são pouco relatados nos estudos.

As respostas referentes aos hábitos vocais mostram certo desconhecimento por parte dos pais quanto aos hábitos nocivos à voz, apesar de observar que alguns pais apresentam noções corretas sobre o tema. Normalmente, os pais e os educadores apresentam maior atenção para problemas na fala e na linguagem, preocupando-se menos com a qualidade vocal e o uso adequado da voz (Souza et al., 2017).

Analisando estes aspectos, vê-se, mais uma vez, a importância do trabalho fonoaudiológico nas escolas e a orientação à pais e educadores. Alguns autores colocam como alternativas, trabalhar essas questões e implantar serviços de intervenção precoce em ambientes escolares, onde o fonoaudiólogo deve orientar os pais e professores sobre saúde vocal (Dias, Oliveira, \& Bastos, 2015). 
A escala RASATI é um instrumento de avaliação vocal muito benéfico para avaliar vozes infantis (Oliveira et al., 2011). Através da análise perceptivo-auditiva da escala é possível identificar alterações ou distúrbio vocais, além de ser eficaz e de rápida aplicação (Pinho \& Pontes, 2002).

Os tipos vocais que mais se sobressaíram neste estudo, foram a soprosidade, seguida de aspereza, rouquidão e tensão. Desse modo, a presente pesquisa mostrou compatibilidade com os estudos de Oliveira et al. (2011) e Martins (2014) que constataram soprosidade e rouquidão de grau elevado em crianças.

A tensão sobrecarrega o aparelho fonador, gerando um padrão hiperfuncional que constitui em um fator de risco para os desvios vocais (Lopes et al., 2015). A soprosidade juntamente com a tensão e a instabilidade são característica comum nas vozes das crianças. A rouquidão é uma alteração frequentemente encontrada, pois é uma característica de quem pratica abuso vocal (Martins, 2014), além disso, é um fator indicador de muitas doenças laríngeas infantis (Oliveira et al.,2011).

\section{Conclusão}

Os dados encontrados neste estudo permitiram concluir que a maioria dos pais percebem alterações vocais em seus filhos e buscam algum tipo de alternativa para melhorar ou tratar tais alterações, porém não conseguem identificar hábitos vocais saudáveis e prejudiciais à voz. Esses dados quando correlacionados com a avaliação perceptivo-auditiva das vozes das crianças, mostram uma concordância, pois houve um número expressivo de crianças com qualidade vocal alterada.

Sugere-se que sejam realizados mais estudos nessa área, envolvendo crianças de outras faixas etárias e buscando uma amostra maior de pesquisa. Além disso, desenvolver ações de orientação às crianças, pais e educadores sobre a importância e os cuidados com a voz.

\section{Referências}

Behlau, M., \& Gonçalves, M. I. R. 1988. Considerações sobre disfonia infantil. In L. P. Ferreira. Trabalhando a $v o z$ (2a ed.) São Paulo, SP: Summus Editorial.

Dias, M. D. R., Oliveira, Â. M. R., \& Bastos, A. C. M. M. 2015. Da garganta vem a voz: Um projecto de educação para a saúde. Revista DIC-Distúrbios da Comunicação, 27, 168-177.

Gomes, A. O. C., Lima, S. J. H., Silva, J. F. D., \& Lucena, J. A. 2016. Hábitos vocais infantis em um Lar de Assistência e Educação: percepção de pais e educadores. Distúrbios da Comunicação, 28(4), 649-657.

Guerra, A. S. H. S., Araújo, A. N. B., Lira, Z. S., Lucena, J. A., \& Gomes, A. D. O. C. 2014. Comportamento vocal de crianças em centro de educação infantil. Distúrbios da Comunicação, 26(1), 101-109.

Lopes, L. W., Lima, I. L. B., Azevedo, E. H. M., Silva, M. F. B. D. L., \& Silva, P. O. C. 2015. Análise acústica de vozes infantis: contribuições do diagrama de desvio fonatório. Revista CEFAC, 17(4), 1173-1183.

Martins, L. R. F. 2014. Disfonias e comportamentos vocais em crianças: revisão de literatura. Trabalho de conclusão de curso (Fonoaudiologia). Florianópolis, SC: UFSC.

Oliveira, R. C., Teixeira, L. C., Gama, A. C. C., \& Medeiros, A. M. D. 2011. Análise perceptivo-auditiva, acústica e autopercepção vocal em crianças. Jornal da Sociedade Brasileira de Fonoaudiologia, 23(2), 158-163.

Paixão, C. L. B., Silvério, K. C. A., Berberian, A. P., Mourão, L. F., \& Marques, J. M. 2012. Disfonia infantil: hábitos prejudiciais à voz dos pais interferem na saúde vocal de seus filhos?. Revista Cefac, 14(4), 705-713.

Paixão, C. L. B., Siqueira, L. T. D., Coelho, A. C., Brasolotto, A. G., \& Silverio, K. C. A. 2015. Há concordância entre pais e filhos quanto a seus comportamentos vocais?. Distúrbios da Comunicação, 27(4).

Pascotini, F. S., Vanessa, R. V., Leris, H. S. B., \& Carla, C. A. 2015. Percepção dos pais acerca do comportamento e características vocais de crianças. Distúrbios da Comunicação, 27(2), 281-287.

Pinho, S. M. R., \& Pontes, P. 2002. Escala de avaliação perceptiva da fonte glótica: RASAT. Vox Brasilis, 3(1), 11-3. Pinho, S. M. R., Jarrus, M. E., \& Tsuji, D. H. 2004. Manual de saúde vocal infantil. Rio de Janeiro, RJ: REVINTER.

Ramos, L. A., Souza, B. O., \& Gama, A. C. C. 2017. Análise vocal na infância: uma revisão integrativa. Distúrbios da Comunicação, 29(1), 20-32.

Ribeiro, V. V., Leite, A. P. D., Alencar, B. L. F. D., Bail, D. I., \& Bagarollo, M. F. 2013. Avaliação vocal de crianças disfônicas pré e pós intervenção fonoaudiológica em grupo: estudo de caso. Revista CEFAC, 15(2), 485-494.

Souza, B. O., Nunes, R. B., Lima Friche, A. A., \& Gama, A. C. C. 2017. Análise da qualidade de vida relacionada à voz na população infantil. CoDAS, 29(2), e20160009.

Takeshita, T. K., Aguiar-Ricz, L., Isaac, M. D. L., Ricz, H., \& Anselmo-Lima, W. 2009. Comportamento vocal de crianças em idade pré-escolar. Arquivos Internacionais de Otorrinolaringologia, 13(3), 252-8. 
Tavares, E. L. M., Labio, R. B. D., \& Martins, R. H. G. 2010. Estudo normativo dos parâmetros acústicos vocais de crianças de 4 a 12 anos de idade sem sintomas vocais: estudo piloto. Brazilian Journal of Otorhinolaryngology, 76(4), 485-490.

Tavares, J. G., \& Silva, E. H. D. A. A. 2008. Considerações teóricas sobre a relação entre respiração oral e disfonia. Revista da Sociedade Brasileira de Fonoaudiologia, 13(4), 405-410.

Teixeira, M. Z. M. 2002. Opinião de pais sobre a voz de seus filhos de 5 a 12 anos. Dissertação de Mestrado (Faculdade de Medicina de Botucatu). Botucatu, SP: UNESP.

Von Fritsch, A., Oliveira, G., \& Behlau, M. 2011. Opinião dos pais sobre a voz, características de comportamento e de personalidade de seus filhos. Revista Cefac, 13(1), 112-122.

Wilson, D. K. 1993. Problemas de voz em crianças. São Paulo, SP: Manole.

\section{Minicurrículo}

Arachane Noronha. Fonoaudióloga graduada pelo Curso de Fonoaudiologia da Universidade de Passo Fundo.

Thais Eloisa Toneli. Fonoaudióloga graduada pelo Curso de Fonoaudiologia da Universidade de Passo Fundo.

Daniela Ferro. Fonoaudióloga graduada pelo Curso de Fonoaudiologia da Universidade de Passo Fundo.

Patrícia Zart. Fonoaudióloga Especialista em Linguagem, aprimoramento em Fonoaudiologia Hospitalar, Mestre em Distúrbios da Comunicação Humana pela Universidade Federal de Santa Maria e Professora do Curso de Fonoaudiologia da Universidade de Passo Fundo.

Luciana Grolli Ardenghi. Fonoaudióloga Especialista em Motricidade Orofacial, Mestre em Distúrbios da Comunicação Humana pela Universidade Federal de Santa Maria, Doutora do Programa de Ciências Médicas da Faculdade de Medicina da UFRGS e Professora do Curso de Fonoaudiologia da Universidade de Passo Fundo.

Como citar: Noronha, A., Toneli, T.E., Ferro, D., Zart, P., \& Ardenghi, L.G. 2020. Disfonia infantil: Análise dos distúrbios vocais em grupo de escolares. Pubsaúde, 3, a032. DOI: https:// dx.doi.org/10.31533/pubsaude3.a032

Recebido: 01 mai. 2020.

Revisado e aceito: 02 mai. 2020.

Conflito de interesse: os autores declaram, em relação aos produtos e companhias descritos nesse artigo, não ter interesses associativos, comerciais, de propriedade ou financeiros que representem conflito de interesse.

Licenciamento: Este artigo é publicado na modalidade Acesso Aberto sob a licença Creative Commons Atribuição 4.0 (CC-BY 4.0). 